\title{
CORPUS Corpus
}

Archivos virtuales de la alteridad americana

Vol 6, No 2 2016

Julio / Diciembre 2016

\section{De la denuncia a la mediación: sensibilidades legales y usos del derecho en conflictos de proximidad}

From complaint to mediation: legal sensibilities and uses of law in conflicts of proximity

\section{Mariana Inés Godoy}

\section{OpenEdition}

Journals

Edición electrónica

URL: http://journals.openedition.org/corpusarchivos/1672

DOI: $10.4000 /$ corpusarchivos. 1672

ISSN: $1853-8037$

Editor

Diego Escolar

\section{Referencia electrónica}

Mariana Inés Godoy, « De la denuncia a la mediación: sensibilidades legales y usos del derecho en conflictos de proximidad », Corpus [En línea], Vol 6, No 2 | 2016, Publicado el 22 diciembre 2016, consultado el 19 abril 2019. URL : http://journals.openedition.org/corpusarchivos/1672 ; DOI 10.4000/corpusarchivos. 1672

Este documento fue generado automáticamente el 19 abril 2019. 


\section{De la denuncia a la mediación: sensibilidades legales y usos del derecho en conflictos de proximidad}

From complaint to mediation: legal sensibilities and uses of law in conflicts of proximity

Mariana Inés Godoy

\section{Introducción}

1 En este artículo nos concentramos en un dispositivo que no ha sido todavía suficientemente abordado desde la antropología social, a pesar de que en nuestro país lleva un proceso de casi veinte años de afirmación en el ámbito institucional de la justicia. Nos referimos a la mediación, un instituto que se enmarca en los denominados Métodos Alternativos de resolución de conflictos (entre los que se encuentran la negociación, facilitación, conciliación, arbitraje, etc.) y que surge ante lo que se declara como un contexto de crisis y emergencia de los sistemas judiciales (véase Matta y Godoy 2016). Bajo los principios ligados a la "voluntariedad", el predominio de la oralidad y la informalidad, un tercero neutral -el mediador- colabora en la comunicación de las partes en conflicto en el horizonte de una solución que redunde en el beneficio de ambas partes, y lo haga en un tiempo mucho menor que el que llevan los procesos judiciales tradicionales.

En el caso de la mediación penal, que es una de las alternativas de este sistema y tiene vigencia en Salta desde el año 2012 (habiendo también mediación civil y comunitaria por ejemplo), este tratamiento se origina en una denuncia policial y es resuelta según consideración de un fiscal del Ministerio Público, incorporando conflictos considerados "menores" por el sistema penal (delitos de amenazas, lesiones, daños, hurtos, usurpación, lesiones por accidente de tránsito, pequeñas estafas, incumplimiento de asistencia familiar, entre varios otros). Estos conflictos, involucran por lo general relaciones de 
proximidad (entre familiares, de vecindad, amistad o simplemente entre "conocidos") y situaciones de violencia cotidiana.

3 Un conjunto de trabajos preceden a este artículo en el estudio de la mediación y la conciliación como modo específico de administración de conflictos desde una perspectiva antropológica, siendo sin duda precursora la academia brasilera. Podemos mencionar el trabajo pionero compilado por Amorim, Kant de Lima y Burgos (2003) sobre la conciliación en los Juzgados Especiales Criminales de Brasil (JECrim), que tenía el objetivo de contribuir a la comparación entre tradiciones procesuales y sistemas de producción de verdad en Brasil. Sobre la mediación y conciliación en el ámbito del Tribunal de Justicia de Rio de Janeiro, Mello y Lupetti Baptista (2011) se preguntaron por la real existencia de una frontera entre lo judicial y lo extrajudicial y por el significado de la palabra "alternativo" cuando la mediación formaba parte del mismo proceso judicial. Sobre esta misma preocupación avanzaron las autoras en un trabajo comparativo con Buenos Aires (Baptista et. al. 2016). También Rangel (2013) contribuyó a entender los aspectos interaccionales entre los conciliadores y otros actores institucionales de un juzgado en Río de Janeiro. En el contexto comunitario son interesantes los trabajos de Simião et al. (2009) sobre la naturaleza de los conflictos que ingresan a los llamados Núcleos de Mediación y Ciudadanía y el lugar que ocupan en la vida de los habitantes de favelas ubicadas en Belo Horizonte. Por su parte, Matta y Godoy (2016) describieron el proceso histórico de implementación de la mediación en Argentina para comprender la particularidad de los casos locales; Matta (2016) indagó en los sentidos de justicia y de vecindad activados en un centro municipal de mediación de una ciudad media de la provincia de Buenos Aires, y Godoy (2016) caracterizó la trama institucional de la mediación penal en Salta en relación a procesos más generales de reformas del sistema penal.

4 En este artículo específicamente nos proponemos problematizar la relación, a la vez de articulación y oposición, entre la lógica que organiza el reclamo inicial, específicamente bajo el dispositivo de la denuncia, y la lógica que informa el tratamiento de dicho reclamo en mediación (penal) como ritual específico de administración de conflictos.

5 Los elementos que se desprenden de este análisis surgen como parte de un trabajo etnográfico realizado en torno a distintos Centros de Mediación del Ministerio Público de Salta-Argentina. ${ }^{2}$ En este caso, hemos tenido en cuenta especialmente la observación de distintas audiencias de mediación penal $\mathrm{y}$, complementariamente, la lectura de un conjunto de expedientes que ingresaron a dicha instancia para su tratamiento. Nuestro interés no radicó únicamente en observar la dinámica de las disputas como se desprendería de una perspectiva procesual en un sentido estricto, sino también en torno a cómo y bajo qué conceptos los propios mediadores o la mediación como mecanismo de administración de conflictos interviene en dichas disputas. ${ }^{3}$ Así, describimos un complejo inter-juego entre ciertos valores de los grupos sociales que dan sentido a sus reclamos y aquellos que movilizan las instituciones y los agentes que intervienen en esta clase de conflictos. Podemos sostener de este modo que el sentido del conflicto y del reclamo judicial se termina de configurar en contacto con estas instituciones en las que la controversia es sucesivamente procesada.

6 Para ello nos resulta, una vez más, fructífero volver a la propuesta de Clifford Geertz (1994) en torno al concepto de "sensibilidades legales". Para el autor, existen formas específicas y culturalmente situadas de entender las relaciones entre hecho y ley. Así, el derecho no es sólo mecanismo sino sentido y conocimiento local, una representación de 
los hechos que está relacionada con marcos más amplios de significación. Al mismo tiempo, en tanto representación de los hechos, "tiene que ser ella misma representada" (p. 202) es decir, ritualizada, y movilizar un cierto lenguaje. Una sensibilidad legal informa los procedimientos y categorías con los que agentes e instituciones operan sobre las controversias en las que intervienen pero también son activadas por los grupos involucrados en las disputas.

7 Por otra parte el derecho, en tanto activa un conjunto de sensibilidades jurídicas, tiene una propiedad de performatividad. Es decir, este no se presenta sólo como un caso privilegiado de control social: "la instancia jurídica no sólo reprime, sino produce" (Kant de Lima 2009, p. 9). O lo que es lo mismo, no sólo "resuelve" (o no resuelve) conflictos, sino también los construye, define los marcos conceptuales y significativos de su resolución. Bourdieu también entendía a la justicia como actos de magia social, cuya eficacia simbólica consistía en "el poder que poseen de actuar sobre lo real actuando sobre la representación de lo real” (1993, p. 4). Y específicamente definía la situación judicial como el lugar de transmutación (Bourdieu 2001). Allí, a partir de lo que llama el artificio de las formas, es decir, de operaciones con el lenguaje, con las categorías, se transforma un conflicto directo en causa judicial, un objeto de controversia en tanto que problema jurídico, un enfrentamiento entre personas directamente interesadas en el conflicto en un debate entre especialistas y en un lugar neutro y neutralizante. Nos interesa en este texto ese proceso de transformación del conflicto y su sentido desde la denuncia a la mediación, y observaremos que esta última intenta una operación inversa a la descripta por Bourdieu para el caso de la justicia tradicional. ${ }^{4}$

8 En definitiva, en este texto, organizado en tres grandes secciones, procuraremos presentar las maneras en que sensibilidades legales específicas se oponen o entran en contrapunto durante el proceso de mediación, produciendo en varios planos la resignificación del sentido de la denuncia inicial. Al mismo tiempo entendemos que estas sensibilidades se activan en tanto existen distintos usos que las personas otorgan alternativamente a estos dispositivos y que predisponen tanto a la demanda como a la participación en una audiencia de mediación. Como veremos a lo largo del texto, no puede comprenderse esta cuestión sino en un marco más amplio de relaciones sociales, pues, como indica Lygia Sigaud (1995), el derecho es frágil como principio de explicación de la demanda judicial.

\section{Cuestiones en la denuncia, cuestiones en mediación penal}

9 En este primer apartado buscamos describir algunos puntos donde puede visualizarse el proceso por el que los asuntos inicialmente presentados en la denuncia para su tratamiento penal son a la vez segmentados, redefinidos y ampliados en la instancia de mediación, afirmando la hipótesis de esta capacidad de la mediación, como ritual singular de administración de conflictos, de reconfigurar los contenidos del conflicto. Al mismo tiempo esta descripción permite que el lector tenga una idea general del tipo de conflictos que cotidianamente trata el sistema de la mediación penal.

Para ello, debemos volver brevemente a la noción significativa de conflicto para la perspectiva del trabajo del mediador en contraposición a la también singular noción de delito que informa la tradición penal y que está contenida en el dispositivo de la denuncia. ${ }^{5}$ 
El conflicto, a diferencia del concepto de delito, reducible a la pura transgresión a las normas y al conflicto con la ley penal, es más amplio y complejo que su tipificación, desde el punto de vista de la mediación, pues incluye la dimensión de una relación social y articula una multiplicidad de dimensiones que no pueden ser captadas del todo por el lenguaje judicial: especialmente la de la desconsideración o la de la falta de respeto (ver Cardoso de Oliveira 2004).

11 Así, el concepto de conflicto habilita una característica central del dispositivo de la mediación penal que es la enorme diversidad de casos que ingresan bajo su tratamiento y cuyo "criterio" de admisibilidad no está del todo resuelto por leyes y reglamentos. ${ }^{6} \mathrm{Un}$ intento de tipologización, que por cierto no es el objetivo de este trabajo, no terminaría de agotar las aristas aparentemente únicas y novedosas de las disputas: "no hay dos conflictos iguales en mediación" según rezan los mediadores.

En cada denuncia que hemos considerado pueden existir uno, o también dos o más delitos en un intento de policías y fiscales de contener la complejidad de los hechos denunciados. En la mayoría de los casos, como enfatizan los mediadores y llego a observar durante las audiencias, esos delitos no llegan a describir los pormenores de hechos, situaciones y sujetos implicados en las controversias e incluso pueden redefinirlos por completo. De modo que en el transcurso del proceso de mediación las demandas, formalizadas en la denuncia, se desagregan en infinitas y milimétricas cuestiones, habilitadas éstas por el ritual de intervención del mediador. Así por ejemplo, la demanda penal por incumplimiento de la cuota alimentaria, que supone inicialmente una negociación por obligaciones económicas, deriva en debates sobre derechos y deberes de cada parte respecto al cuidado de los hijos, reclamos relativos al reconocimiento de lo que unos y otros efectivamente hacen o aportan, sobre la participación e incluso control de esa organización, etc. Y se deslizan con bastante facilidad, bajo la forma de una negociación en términos de los hijos, evaluaciones sobre el comportamiento de la otra parte: la ex mujer o el ex marido, envolviendo estas evaluaciones ciertas concepciones morales y de género.

Otro ejemplo de esta emergencia de asuntos en mediación no tenidos en detalle en la denuncia se presenta en los casos de accidentes de tránsito que involucran el delito de lesiones. La orientación del proceso a una reparación económica, que puede permitir saldar la falta penal asociada a la lesión, se puede articular con un "pedido de disculpas" a la víctima como dispositivo también de resarcimiento penal, ofrecido de manera personal y constando en el acta escrita de acuerdo. Y el relato en mediación se concentra en los pormenores de los golpes y heridas, sus tratamientos y secuelas, los bemoles en la vida laboral o de lucro cesante del afectado, sobre el trauma emocional que implicó el hecho y reclamos por haber actuado de manera negligente con la víctima una vez ocurrido el hecho ("ni siquiera me fue a ver" al hospital). Así las negociaciones resultan en un proceso engorroso y trabajoso para el mediador, que no descuida ni demandas por pequeños o grandes montos de indemnizaciones ni traducciones confusas y superpuestas con éstas en torno a nociones de desconsideración en los reclamos.

Por otra parte, si en la denuncia se deben consignar claramente víctimas y victimarios $u$ ofensores del hecho en cuestión, en mediación se presenta la imposibilidad de delimitar claramente estos roles. $\mathrm{Y}$ asimismo, a pesar de que no parecen existir a priori asimetrías de poder marcadas entre acusado y acusador, esta proporción no está resuelta por el reclamo inicial sino que es también un aspecto de gran importancia para las partes que necesita redefinirse en el proceso de mediación. 

física, verbal y amenazas de agresión en torno al ámbito de relaciones primarias, de vecindad, de amistad, laborales o sentimentales caratulados como amenazas, lesiones o daños: golpes de puño de una mujer que acusa a otra, compañera de estudio de su marido, de mantener relaciones con éste; amenazas por una disputa por la medianera; una pelea entre el dueño de una camioneta que hace reparto de carne en una carnicería y un vecino que le reclama que estaciona la camioneta en su garaje; una acusación de una mujer contra su hija por supuestos golpes reiterados; la acusación a un supuesto desconocido por haberle arrojado un botellazo en la cabeza durante una fiesta; la agresión de un puntero político a una empleada de la municipalidad, etc.

Más bien estos roles -el ofensor y la víctima-, definidos bajo la formalidad de la denuncia, se significan y renegocian en el mismo proceso de mediación, haciéndose en no pocos casos reversibles y entonces negociándose las fronteras morales que definen a uno y otro. Incluso el mediador, para su estrategia de acercamiento y comunicación entre las partes, explota este contexto indefinido y puede ayudar a configurarlo también. Como observadora también he notado esto en los casos de accidentes de tránsito, donde a priori pareciera que el hecho y la responsabilidad en cuestión son inobjetables. Sin embargo, durante las audiencias se abre la posibilidad de un enorme contraste y disidencia en el relato respecto a las circunstancias del episodio. En un caso el ofendido reclamaba en audiencia de mediación que mientras andaba en bicicleta fue embestido por un auto, que a raíz de esto tuvo un esguince que lo dejó sin posibilidades de trabajar durante tres semanas, y que rompió en el accidente sus anteojos. El acusado adujo que fue el reclamante quien no tenía frenos en su bicicleta, y que si bien tuvo que frenar de golpe, la bicicleta "lo chocó a él", al no tener activos los frenos. Que su auto se dañó en su óptica y luz de giro, que además cuando se bajó a auxiliarlo éste le tiró un zarpazo que lo rasguñó en el rostro, que por evitar la agresión él cayó hacia atrás y estuvo dolorido varios días.

En este sentido, hemos notado cómo, según la perspectiva, el ofensor se trastoca en afectado o al menos describe situaciones que pretenden indicar una corresponsabilidad en el hecho de ambas partes, tornando compleja la definición de un acuerdo de resarcimiento. Esta particular configuración del proceso se condice a la vez con el hecho de que en no pocas ocasiones las disputas se encarnan en una serie de denuncias cruzadas entre las partes en conflicto, cuestión que trataremos en otro apartado.

Por otra parte, en los casos de amenazas, por momentos la relación "víctima" y "ofensor" parece desbordarse a otros implicados. Así por ejemplo, a partir de una denuncia de una mujer contra la sobrina de una vecina y la propia vecina por amenazas a su hija, en el relato durante la audiencia se agrega que su hija también se siente amedrentada por un hijo de la misma vecina, quien aparentemente la molesta porque no quiso salir con él. Y se desprenden asimismo otras acusaciones que no parecen ser el asunto directo del delito en cuestión: que la acusada -o bien la denunciante, según de quien venga el relatovende drogas, que tal hijo es adicto al porro, que en otra ocasión le apedrearon la casa, que tal está en negocios turbios, o son una familia de "malos hábitos", la casa del acusado es un "aguantadero", es decir un lugar de venta de drogas o donde se juntan a tomar, que tal persona no sólo agrede a los vecinos sino a miembros de su propia familia. Asimismo, la preocupación por la agresión personal puede expresarse en términos más generales: "mi preocupación es en qué se puede convertir el barrio", porque "esta vivienda no va a valer lo que yo estoy pagando". Y poner en juego no sólo al individuo agresor sino a unidades sociales más amplias en conflicto: no es sólo la persona que agrede sino la 
familia la que tiene malos hábitos, no es su persona la afectada sino también la de sus hijos y la de los otros vecinos.

Por otra parte, especialmente en ciertos casos, surge un proceso de mutación donde complejas cuestiones legales y financieras incorporadas a los reclamos pueden ser reducidas, bajo la concepción y ritual de la mediación, a los términos de individuos concretos enfrentados por intereses que de todos modos pueden componerse. Es el caso de acusaciones de estafa o de comportamientos presuntamente fraudulentos de individuos o de empresas, sociedades comerciales o de servicios contra sus clientes. Tenemos por ejemplo un caso que involucra la compra de un camión cuyo pago se hizo con cheques sin fondo o una acusación por parte de una mujer de que su inquilina no le pagó el alquiler por tres meses y adicionalmente no le devolvió el dinero que le prestó para comprar ropa para vender. La de una mujer contra un técnico informático que le habría cambiado el disco rígido original de su computadora por uno de menor valor. $\mathrm{O}$ una causa contra el administrador de un consorcio de un edificio por administración fraudulenta por parte del nuevo administrador, acusándolo de no haber realizado pagos de la AFIP, aportes sindicales y servicio de seguridad durante determinado periodo, entre muchas otras causas similares.

En todos estos casos el mediador debe procurar familiarizarse con aspectos técnicos como pedidos de secuestro, prendas, cuestiones de intereses, sistemas de pago, auditorías contables e incluso lidiar con la existencia de importantes montos de dinero en juego y la común presencia de abogados acompañando a las partes. Y sin embargo, las discusiones sobre la indemnización económica y sobre la ilegalidad del acto en cuestión se mezclan en la mediación con evaluaciones sobre la ilegitimidad del comportamiento del ofensor que podrían comprenderse bajo el concepto de "insulto moral", de Cardoso de Oliveira (2004), es decir, de la ofensa cuando se han interrumpido unilateralmente los términos del intercambio. Esta cuestión aparece en este grupo de casos, en el frecuente uso de conceptos como "traición de la buena fe", "abuso de confianza", "infidelidad", etc.

Acerca de estos desplazamientos de ciertas nociones propias del sistema penal en la mediación y la incorporación de sistemas de significado diferentes e incluso opuestos a los contenidos en el primero, son interesantes los conflictos de hurto y robo, donde se dirime la sustracción o pérdida de objetos de propiedad de otros o de patrimonio. En un hecho calificado como robo, una mujer indica que su hermano violentó la puerta de su habitación y le extrajo varios elementos de su propiedad en la casa que comparten de sus primogénitos y que está en trámite sucesorio. Una denuncia de hurto también involucra el ámbito familiar: se trata de una madre que acusa a su hijo menor, al que describe como adicto a las drogas, de sustraerle de su casa un secarropas. En otra denuncia bajo el mismo calificativo la denunciante involucra a su vecino, quien trabajaba de chofer de remís en el auto de su propiedad el cual dejó abandonado sin la ticketera digital y sin la radio con handy. En otra acusación, un hombre indica que dejó mucho tiempo una camioneta en el terreno del denunciado y éste se la vendió. A su vez en la denuncia se indica que el denunciado alega que el denunciante le habría dado en pago la camioneta, poniendo en duda la acusación inicial. Un aspecto importante de estos casos es que la mediación supone concentrarse en la devolución de la cosa, una compensación de la cosa pretendida o un intercambio, desplazando la idea de sanción o de la búsqueda de probar la verdad de los hechos para incorporar en cambio la noción de responsabilidad. Desde el punto de vista de los mediadores, la "verdad" como verdad real de los hechos, propia de los sistemas penales, es algo que "le interesa al fiscal, no a los mediadores". Si existe una verdad aquí, 
se trata de una "verdad consensuada" por las partes. En contraste, el concepto de "asunción de responsabilidades" en mediación penal no implica que el acusado reconozca que ha robado un celular, por poner un ejemplo, sino que puede directamente decir en una audiencia de mediación: "bueno, ya no está el celular, qué hacemos para cerrar este problema con la justicia". Hay entonces una "asunción de responsabilidades solapada", y esa responsabilidad se construye, se limita alrededor del interés de la víctima. Si para la víctima la propuesta que surge del proceso es suficiente para el resarcimiento de su interés, si compensa la ofensa sufrida, se ha definido una responsabilidad suficiente. $Y$ es así que los objetos que demandan haberse sustraído o retenido indebidamente, se pueden compensar con otros, habilitándose un universo de transacciones e intercambios significativos y creativos entre supuestas víctimas y ofensores impensados en la lógica de la acusación penal inicial.

En fin, en este apartado hemos querido mostrar cómo en torno a distintos grupos de casos, la mediación habilita un conjunto de mecanismos y de conceptos que dan lugar a la incorporación de dimensiones del conflicto que en cambio difícilmente quedan expresadas en la denuncia penal, tensando sensibilidades jurídicas diversas.

\section{El sentido de la denuncia y la mediación frente al conflicto}

En el contexto de su manifestación bajo el dispositivo de la mediación nos preguntamos por el valor que tiene la denuncia por la cual todo el andamiaje jurídico se moviliza, especialmente si tenemos en cuenta que en un porcentaje muy alto, para preocupación de los mediadores, los denunciantes y denunciados no comparecen a las audiencias de mediación. ${ }^{7}$ Bourdieu recordaba que "nada es menos natural que la necesidad jurídica" o el "sentimiento de tener derechos", agregando que "la sensibilidad respecto a la injusticia o la capacidad de percibir una experiencia como injusta no está uniformemente extendida..." (2001, p. 194). Pero Bourdieu atribuía demasiada eficacia al papel de los "especialistas" - abogados especialmente- en el paso de ese sentimiento de injusticia al acto de la demanda judicial. No sólo que en este tipo de causas de "pequeña monta" el rol del abogado es ciertamente secundario y así lo promueve la propia mediación, sino que estimamos que existen otras mediaciones que es necesario considerar. Estamos más cerca en este sentido de la propuesta de Lygia Sigaud, quien analizó el universo de relaciones sociales y de concepciones morales que alentaban o desalentaban a recurrir a la justicia para resolver determinados conflictos o el reclamo de derechos, en la premisa de la posibilidad de un uso social del derecho y de su eficacia como regulador social (Sigaud 1996 y 2004). Según su hipótesis "deudas morales tienden a anular las deudas jurídicas" (Sigaud 2004, p. 133). Es decir que, cuando existían lazos personales y de obligaciones mutuas entre las partes, sentimientos de deuda, gratitud, respeto, o por ejemplo referencias a la bondad y generosidad de la otra persona (el buen patrón en el caso de estudio), actuaban como mecanismo coercitivo (moral y emocional) frente al reclamo judicial, que en caso de hacerse podía interpretarse para el demandado como una traición y el demandante terminar cargando con un sentimiento de vergüenza. En cambio existía la predisposición a una demanda judicial en una configuración de relaciones impersonales y de jerarquía respecto al demandado, representándose este acto bajo el apelativo de coraje. 
24 En el conjunto de apartados que siguen trabajaremos sobre 1) la relación entre el concepto general de "conflicto" para las partes, asociado a un atributo social y personal y el que promueve la mediación; 2) la tensión entre cierto sentido público inserto en lo que llamamos la lógica del desafío que parece contener toda denuncia que se canaliza a la justicia y el trabajo de relativa privatización del conflicto en mediación; 3) la diversidad de expectativas y la gran carga puesta en el acto de la denuncia por parte de las personas trenzadas en conflicto, y el contraste, transformación y a veces superposición de esas expectativas con las que promueve el proceso de mediación; y 4) las relaciones sociales y concepciones morales que contextualizan la evaluación sobre la eficacia de la demanda judicial o sobre la necesidad de interrumpirla. Todos estos aspectos vuelven a introducir la pregunta por las sensibilidades legales puestas en juego por operadores y demandantes y demandados, capaces de re-definirse en relación contemporánea con estas alternativas institucionales.

\section{1. El conflicto como concepto negativo y su significado en la mediación}

En la antropología jurídica clásica, Robert Redfield da cuenta, en lo que llama "derecho primitivo", de cómo a algunos pueblos les gusta litigar y a otros no. Así por ejemplo, los ashanti de África "son muy afectos a litigar siendo para ellos los litigios una especie de deporte o arte y un fin en sí mismo" (Redfield 2005[1941], p. 38). Al mismo tiempo existen sociedades donde se ve con desprecio que alguien se halle envuelto en un conflicto: "La mejor alabanza entre ellos es la de poder decir que fulano 'es un hombre bien educado. Que nadie tiene queja de él. Que nunca se enreda en disputas"' describe respecto a los indios zuñi (p. 23). Y sin embargo también sugiere que este es un caso más bien excepcional, porque "en muchas sociedades primitivas, todos tienen derecho a defender sus derechos o los de sus parientes, aunque causen con ello un gran alboroto" (Redfield 2005, p. 23). El caso extremo es en sociedades donde el desquite ilimitado como defensa de derechos supone una obligación a riesgo de ganar el desprecio o no ser respetado por los demás, incluso alguien así podría ser acusado de cobardía y llamado "mujer" (p. 29).

Contemporáneamente y más cerca de nuestro caso, en el trabajo citado de Simião et. al (2009) en torno a favelas de Belo Horizonte, se encuentra que en la ética o sensibilidad jurídica local, el conflicto, e incluso la agresividad (no entendida necesariamente como violencia) es una forma legítima de sociabilidad, de construcción de las identidades de un grupo frente a otros, de la afirmación del respeto recíproco e incluso de las relaciones jocosas. Y que asimismo también cobra legitimidad la punición para resolver un conflicto (que además se percibe de manera diferente a la criminalización). La reflexión de los autores es que esta ética se opone a la ética jurídica de la justicia restaurativa representada por los Núcleos Comunitarios de Mediación existentes en la favela, centrada en valores como la pacificación, las relaciones armónicas y la necesidad de extirpar el conflicto del tejido social.

27 En contraste con esta descripción o agregándole complejidad a la relación entre la concepción sobre la disputa y su sentido en mediación, hemos notado cómo, a pesar de la cantidad de casos que se inician con una denuncia expresa, existe una llamativa regularidad con la que las personas durante las audiencias de mediación, ya sean denunciantes $u$ ofensoras, realizan distintas referencias con las que parecen buscar ser apartadas, al menos frente al mediador, de cualquier grado de asociación con el atributo 
de "ser conflictivos": "Yo nunca tuve un conflicto o un problema con nadie"; "es la primera vez"; "pregunte en el barrio si alguna vez tuve problema". Nos acercamos en este caso al contexto interpersonal de vecindad y de mayor o menor valorización de la naturaleza del vínculo. "Yo dono juguetes para el día del niño", indica una mujer en una audiencia con el mediador, y se comprende de ahí el sentido de ofensa de haber sido denunciada: "me llega a doler embarrarme como me embarró".

Queremos destacar que la atribución negativa de la noción de conflicto por parte de estos sujetos al menos se contrapone con la positividad que pretende asignarle la mediación, es decir, entendiendo ésta última el conflicto como un resultado "normal" de la interacción social y como "oportunidad" para la transformación de la relación.

Las personas en las audiencias de mediación también suelen usar la expresión "No quiero tener problemas" o "yo no quiero tener problemas con él" cuando aceptan un acuerdo, piden que se acepte una propuesta o proponen el cierre del proceso. Este concepto negativo asociado al conflicto puede también ser un atributo personal de sus oponentes. Así una mujer aclara que no tiene relación con su vecina porque es una mujer "muy especial", "muy conflictiva". En un caso de lesiones por accidente de tránsito no se conocían ofensor y denunciante, pero el hecho había ocurrido en el barrio donde vivían tanto la víctima como la madre del acusado. El acusado parecía interesado en cerrar de manera presurosa y económica el proceso, evitando también prolongar el conflicto con la otra parte, pues según le habían comentado "proviene de una familia conflictiva". De este modo se conducía en la mediación de modo de cortar relaciones con una persona con la que el accidente armó fortuitamente un vínculo directo.

\subsection{Lo privado y lo público en la denuncia y en la mediación}

La mediación penal se origina indefectiblemente con una denuncia policial o en cualquier otro ámbito de la justicia habilitado para ese fin. Se trata de un dispositivo que debe referir a hechos o circunstancias que están tipificados como delitos por la ley. Además, en ella debe poder individualizarse a las "partes": "víctima/s", "ofensor/es", y en algunos casos se agrega el denunciante como una persona distinta a la víctima. Es decir que la denuncia a la que nos referimos aparece en los términos de sujetos individuales trenzados en conflicto y donde el delito es atribuido a un responsable.

Hemos anunciado sin embargo, que la identidad del hecho y de las dos partes se complejiza en múltiples actores y episodios durante el proceso de mediación.

Es interesante este contrapunto entre las dimensiones de lo público que comporta la denuncia y lo aparentemente privado de la mediación. Así, muy pocos de los episodios que describen estos expedientes han sido objeto de noticias en los periódicos locales, y tampoco suelen llevarse a reclamos en el espacio público ${ }^{8}$ por sus marcados contornos domésticos, su ausencia de espectacularización, su faltante de violencia extrema, sus actores prácticamente anónimos. Y sin embargo, hay una dimensión pública que comporta una denuncia, así sea sobre un acontecimiento ocurrido en el espacio de la intimidad, en contraste con el proceso de privatización del conflicto que supone el ritual de mediación. Veremos esta cuestión.

En el aspecto del derecho penal, lo público remite a la noción elemental de crimen, donde lo que se concibe es que el acto en consideración ha afectado el interés público o al cuerpo social, además de a la víctima, y cuyo mecanismo de resarcimiento corresponde a una 
sanción punitiva. El elemento privado del derecho, comúnmente identificado con el derecho civil, supone que hay zonas de ofensas que atañen más bien a los individuos, donde una persona que ha sufrido un maltrato en sus derechos puede obtener reparación o restitución de la persona responsable. Y donde la conducta del acusado se define en términos de daño, propiedad o principios de indemnización. Este último, a rasgos generales comprende el principio de la mediación, tanto civil como penal. Es decir, por más pública que se suponga la noción de delito que habilita una denuncia o incluso la investigación del Ministerio Público, ese conflicto, para su tratamiento en mediación, se entiende en los términos de una disputa entre partes (individuos) y la pretensión de la sanción del Estado es reemplazada por la posibilidad de la composición de intereses y reparación de la ofensa por parte del mismo ofensor, en acuerdo con el ofendido. Este proceso, que aunque comporta un alto grado de dramatización oral del conflicto, ocurre en una sala de audiencias y a puertas cerradas, donde sólo pueden estar presentes las partes y el mediador (a excepción de que con el consentimiento de las partes puedan participar otras personas que se consideran pertinentes al problema), se encuentra completamente resguardado bajo cláusulas de confidencialidad, incluso respecto a la intervención de otras autoridades públicas de la justicia.

Al mismo tiempo, podríamos decir que la dimensión pública de la denuncia se emparenta con la lógica del desafío que marcaba Pitt-Rivers (1979) en las disputas de honor, pues como desarrollaremos más adelante, con la denuncia no sólo es la institución quien sabe de la acusación sino también los otros vecinos. Siguiendo al autor, el honor como sentimiento y estado moral que indica un derecho de posición, una validación de la imagen que se estima de sí mismos y por contraposición un derecho a determinado trato a cambio, si bien se trata de un sentimiento personal, exige un reconocimiento público, por lo tanto sólo puede verse comprometido en presencia de testigos y reclamarse públicamente. Además, si bien se trata de un atributo individual, está relacionado con las solidaridades sociales, comprometiendo a grupos como la familia, el linaje, etc. En nuestro caso observamos también la presencia de unidades sociales involucradas en el conflicto mayores que el propio individuo actuante como parte. Volviendo a Pitt-Rivers, el duelo es por definición el mecanismo por el cual se resuelven las ofensas de honor. En el duelo, la parte ofendida lanzaba un desafío al ofensor mediante el cual exigía satisfacción. En ese caso el ofensor se veía obligado a retractarse y a pedir disculpas o bien a aceptarlo. Es interesante que Pitt-Rivers señala el conflicto existente entre honor y legalidad: "recurrir a la ley en busca de desagravio es confesar públicamente que te han agraviado y la demostración de vulnerabilidad pone en peligro tu honor" (p. 29), aunque en nuestro caso se advierte la articulación entre una demanda por la ofensa personal o de derechos vulnerados y el reclamo judicial.

Contemporáneamente Cardoso de Oliveira (2004), al analizar conflictos tratados en instancias de conciliación en Estados Unidos y Brasil, sostenía la hipótesis del paso de los conflictos por el honor a otros por el valor de la dignidad en el contexto moderno de individualismo y ciudadanización. Esta interesante observación del autor no nos parece que impugne, como iremos viendo a continuación, esta analogía con la cuestión del honor para entender el espíritu de la denuncia.

36 Al respecto debemos sospechar que no todos los grupos sociales procuran ventilar distintas clases de problemas más o menos domésticos frente a la autoridad policial del barrio ni tampoco llegan a comparecer a mediación por mera invitación. Así es que esta tensión entre lo público y lo privado del conflicto y su tratamiento también puede 
presentarse en los términos de la burocratización del conflicto o de la demanda versus su resolución sin la intervención de un tercero institucional. Y también de la perspectiva componedora de la mediación versus la solicitud de sanción de parte de quienes llegan a esta instancia. Todas cuestiones que evidencian el conflicto entre sensibilidades legales específicas sobre las que volveremos en los apartados que siguen.

\subsection{Usos de la denuncia y la mediación}

Por los casos observados en audiencias de mediación, inferimos que la denuncia inicial contra quien es señalado como ofensor o victimario puede ser un simple trámite para pasar al proceso judicial, sobre el cual se tiene una clara y significativa expectativa. Esto parece presentarse en personas que pueden movilizar mayores recursos económicos y jurídicos. En otros casos la denuncia en cambio parece convertirse en un dispositivo de relevancia en donde recaen las expectativas de reconocimiento institucional del reclamo, de dramatización pública del conflicto interpersonal, con base en la autoridad policial. Es interesante que si bien en Salta se han extendido los centros de mediación en barrios y localidades del interior, una cuestión que los mediadores recalcan es que no se ha logrado aún que las personas canalicen un conjunto de controversias directamente en los centros de mediación en vez de recurrir a la instancia policial. Este dato en principio nos llama la atención y debe ser profundizado, porque en cambio existen distintas etnografías sobre formas de administración de conflictos y de la violencia interpersonal en el ámbito barrial de zonas periféricas de Argentina y Brasil, donde se señala que el recurso a la policía es poco frecuente, y que incluso puede traer represalias (ver Simião et. al. 2009, Garriga Zucal 2007, Auyero y Berti 2013). ${ }^{9}$

De este modo la denuncia se constituye por ejemplo en un medio para la búsqueda de seguridad personal. Una denuncia por amenazas se produjo de parte de una señora contra un joven vecino que tenía la reputación de mantener permanentes problemas con la ley: "vive en la alcaldía" según expuso la víctima en mediación. Además precisó que a partir de la denuncia "nos dejó de molestar". En un sentido parecido la denuncia puede servir como mecanismo de interrupción de la agresión o para reequilibrar la relación de asimetría que la agresión puede haber promovido: "yo pensaba que con la denuncia se podía calmar las cosas, que era una manera de llamarle la atención", indica un denunciante también en un caso de amenazas. En este caso también parece existir una cierta inhibición moral para solucionar el conflicto a través del uso de la fuerza directa, sin intermediarios:

Yo trompearme con él no me sirve porque eso va a llevar a algo más. Yo no soy de pelear, pero que haya apedreado mi casa, una cosa son los insultos, yo sé cómo es, yo vengo del Barrio Unión, pero podría haber pegado en el vidrio de la habitación de mis hijos y herirlos, yo también tengo arma, yo en ese momento tenía ganas de romperle la cabeza.

También la denuncia puede percibirse como un propio y conclusivo medio de castigo o sanción al ofensor: "La próxima lo va a pensar dos veces antes de hacerlo" se precisa en una denuncia por estafa. A veces ésta funciona como forma de cortar la relación: "Lo denuncié y nunca más le hablé”. Y también se puede buscar en ella una reparación, aspecto en el que la mediación pone su énfasis. En ninguno de estos casos el denunciante necesariamente se ha representado las posibles consecuencias burocráticas de ese acto, incluso la de tener que participar de un proceso de mediación con su agresor u oponente. 
Y asimismo hemos notado cómo los mismos principios que alientan a un reclamo en la denuncia inicial generalmente son los que predisponen a la participación en mediación: cuando esta instancia parece resultar en la primera y única convocatoria institucional a un reclamo; ${ }^{10}$ cuando se juzga eficaz como método para resolver en el corto plazo una ofensa, agresión o pérdida de algún patrimonio; cuando se espera de ella la oportunidad de que de allí salga un castigo ejemplar para el acusado ocurriendo entonces frustraciones ante el no ofrecimiento de este tipo de alternativas sancionatorias; ${ }^{11}$ cuando la mediación llega a representar para la "víctima" la posibilidad de resguardo de su seguridad personal o la de su familia; cuando hay un vínculo significativo que se estima recomponer. Sobre este último caso, una mujer indica en una audiencia que prefiere que el tema se arregle en mediación antes que proseguir en la justicia "porque es el hijo de mi vecina de hace años". De este modo la instancia de mediación puede servir para interrumpir el proceso judicial que la denuncia no imagina ni prevé (generalmente a partir de un acuerdo o de una manifestación de desistimiento de la acción penal).

\subsection{Denuncia, reciprocidad y relaciones sociales}

41 Otra dimensión importante de considerar respecto a la denuncia es cuando ésta funciona como arma de ataque o contraataque y desencadenante de un nuevo conflicto. Esto parece presentarse especialmente en los casos de conflictos en el ámbito familiar y de agresiones entre vecinos. Denuncias que van y vienen, denuncias de "falsa denuncia", expedientes que se conectan con otros donde "víctimas" y "ofensores" cambian de roles según cuál expediente se mire. Expresiones de venganza a partir de la denuncia: "vos me denunciaste entonces yo también te denuncio"; "yo la denuncié porque ella me denunció primero", registro respecto a un conflicto entre hermanas. Según una mediadora, las personas no toman en serio las denuncias porque saben que no serán resueltas. Y sin embargo son así de persistentes e incluso se convierten en motivo de ofensa: "Me llega a doler la manera en que me embarró" (en referencia a haber sido denunciada por su vecina). Los mediadores nos explican cómo es necesario, para su estrategia de acercamiento de las partes, apartar la excesiva concentración que éstas pueden mostrar en el concepto de que "me hizo una denuncia", o incluso que "me hizo un juicio", hecho que se actualiza con la citación de la policía a una audiencia de mediación penal (ver Godoy, 2016).

Podríamos pensar la denuncia o acusación en este sentido casi como una forma de intercambio (Mauss 1979) o, inversamente, a relaciones de intercambio tejidas sobre la base de la acusación. De algún modo esto ha sido pensado por antropólogos como Max Gluckman ante conflictos en el contexto de relaciones interpersonales. Para Gluckman la delación por ejemplo a través del chisme o el escándalo se conectaba tanto con las disputas por prestigio y posicionamiento social al interior de un mismo grupo como con la manutención de la unidad de los grupos y su moralidad. Los valores se afirmaban y persistían en estas acusaciones y animosidades personales y al mismo tiempo en ellas se marcaba cierta membresía de grupo, de modo que "los otros miembros están excluidos de esta guerra de escándalos" (Gluckman 1963, p. 312). En definitiva, la acusación comprendía el privilegio de una relación social cercana.

43 En los casos analizados, generalmente la relación de asimetría acentuada por la agresión o la amenaza de agresión o bien la humillación puede inhibir la posibilidad de exponer públicamente la ofensa, a excepción por ejemplo de que lo haga un tercero (la madre de la 
víctima es una alternativa bastante recurrente en el caso de los jóvenes). Pues se percibe que el reclamo judicial portaría un riesgo mayor para la persona agredida: "no quiero tener problemas" expresan las personas cuando optan por cerrar el proceso. Lo mismo ocurre cuando la superioridad en la posición social de quien ha sido ofendido respecto al agresor, impide cualquier posibilidad de intercambio que surja de la mediación: “¿Qué le puedo pedir? Preso no va a ir. Plata voy a estar años para sacarle algo" indica un joven que denunció haber sido agredido por varios hombres con una piedra en el parabrisas de su auto cuando iba con su esposa y bebé a raíz de un pequeño incidente vial, daño que además pudo solucionar por sus propios medios: "el auto tenía un seguro completo, al otro día ya tenía puesto un parabrisas nuevo". Es así que el denunciante manifiesta a la mediadora respecto a su agresor que "no le interesa siquiera verlo" y que "no quiere tratar nada con él". Lo mismo parece ocurrir en un conflicto en un "barrio country" de Salta entre dos vecinos que según la mediadora eran "de muy distinta clase social", uno de ellos de mayor estatus, como casi todos los habitantes del barrio, y el otro, un mecánico que además ejercía su oficio en el mismo barrio y "tenía muchos perros". Un altercado por el tema de los perros derivó en golpes y en la rotura del vidrio de la camioneta de uno de ellos. Si el mecánico estaba dispuesto a llegar a un acuerdo de respeto que además le permitiera no seguir teniendo problemas con la justicia, el otro vecino -según explicaba la mediadora-, con un sentido de poder y superioridad -"no sabe con quién se metió"- y con la posibilidad de contar con un buen abogado estaba convencido de la alternativa de conducirse a un juez, desistiendo de la mediación. En fin, este término de la distancia social y la imposibilidad del tejido de intercambios o su interrupción explica entonces ya sea la inhibición al reclamo a través de una denuncia como la oclusión de una predisposición a la mediación.

A este respecto es interesante el caso de una madre que denunció a su vecina por amenazas, a raíz de las constantes vejaciones de la sobrina de esta vecina, que vivía con ella, contra su hija. La agresión y humillación permanentes a la que, indicaba, se sometia a su hija, proveniente además de alguien que no formaba parte del núcleo familiar histórico de la vecina contigua, había quebrantado la relación de reciprocidad, así fuera mínima, que existía entre estas vecinas (en cuyos relatos aparecen algunas situaciones, aunque escasas, de ayuda mutua y más bien de tolerancia, en ese marco de la vecindad, de parte de la denunciante a que su vecina y sus hijos tomaran alcohol o fumaran porro en la vereda). ${ }^{12}$ La relación de reciprocidad previa con la vecina no logró compensar el trato violento y degradante contra su hija, y los perjuicios que éstos le trajeron para su vida personal y social.

Por último debemos decir que de la denuncia también puede desistirse por causas variables, como cuando la situación habitacional que ligaba a las personas en conflicto varió y se distanciaron unas de otras; cuando pasó demasiado tiempo desde la denuncia y la primera audiencia de mediación y el conflicto terminó por extinguirse, por perder valor. O simplemente cuando por motivos laborales o familiares no se puede asistir a las audiencias: "Prefiero cerrar el proceso, porque se me complica venir por los chicos". Es decir, cuando ya sea por la propia dinámica local o de la burocracia judicial se han disipado los compromisos morales entre las partes que hacen significativa la ofensa. 


\section{Estrategias de moralización del vínculo y para dar legitimidad al reclamo} legitimidad del reclamo a partir de situarse a su vez como víctima legítima. ${ }^{13}$ Esto puede ocurrir tanto con el denunciante como con el acusado, pues como expusimos, las acusaciones se tornan por momentos intercambiables. "Yo tengo buena relación con mis vecinos" indica un reclamante, como con eso agregando veracidad a su relato; él en cambio es una "persona de vicio". Traducida esta segmentación también entre un nosotros que porta una "cultura del trabajo" y los denunciados, que tienen una "cultura del vicio" (el alcohol, la droga, la joda); entre una "casa de familia" y un "aguantadero". La división entre "buen" y "mal" vecino a veces puede coincidir con el "viejo" y el "nuevo" vecino: "desde que ellos llegaron, se han multiplicado los casos de robo en la cuadra". Recordemos que Elias (1997) trabajó de manera sugerente este tipo de configuraciones sociales y lo que llamó una sociodinámica de estigmatización trazada por la antigüedad de residencia en el lugar como definitoria medida para la atribución de superioridad en cuanto a rango y honra de las familias obreras viejas, "los establecidos", y la inferior respetabilidad y estima de los "recién llegados", carentes de virtud, burdos, poco educados, sucios, y además anómicos, según la perspectiva de los establecidos.

Es significativo que la intervención de la policía ante reclamos por agresiones en el ámbito vecinal también puede introducir este tipo de clasificación. Así, en una parte de un expediente penal donde la policía aporta datos a la fiscalía se precisa que:

el personal policial realizó diversas entrevistas en el barrio, manifestando los vecinos que la acusada es mala vecina, irrespetuosa, y los menores de la misma son maleducados, dañinos, que constantemente insultan a los chicos del barrio y a personas mayores, como así también apedrean los domicilios, pudiendo observar que los mismos se encuentran en la calle hasta altas horas de la noche. Respecto a la denunciante expresaron que no tuvieron inconveniente con la misma, agregando que es buena vecina". (Expediente de mediación penal. El destacado es nuestro).

Y el mediador se enfrenta también a la posibilidad de construir distintos universos morales en torno a las partes en conflicto. En una reunión de intercambio entre mediadores, una mediadora manifiesta haberle costado la "neutralidad" ${ }^{14}$ en la mediación ante un un caso de usurpación de un terreno. La denunciada, acusada de ocupar un terreno de propiedad de la denunciante, era, según el relato de la mediadora sobre cuya propia percepción procuraba reflexionar, una chica que tenía toda "esta idea asociada a los derechos" restando el papel a las "obligaciones" y al "trabajo" y acostumbrada a infringir todas las leyes. La contraponía en cambio con la empleada que cuidaba a su hija, una "chica trabajadora" que fue generando pequeños logros a partir de su propio esfuerzo.

Al mismo tiempo, para hacer que la estrategia de mediación resulte eficaz el mediador debe cargar de algún modo de valor moral al vínculo, reduciendo la supuesta hostilidad 
originaria entre las partes y generando una proximidad que no necesariamente existía de hecho. Esto se observa incluso en procesos de relaciones sociales de un mínimo preámbulo de obligaciones y derechos vinculantes, como es el caso de los conflictos por accidentes de tránsito, donde por generalidad las personas no se conocen antes de ocurrido el incidente.

Más sencillo parece este cometido ante conflictos que involucran relaciones de vecindad: "ella dice que usted es buena vecina", indica un mediador en referencia a los supuestos dichos de la denunciante, quien parece reconocer el origen de la disputa no directamente en la vecina denunciada sino en una sobrina de ésta que mora últimamente en su casa. Sobre este contexto de relaciones vecinales el antropólogo Juan Pablo Matta (2016) analiza, a partir de un caso observado en audiencias de medición, de qué modo emergen allí definiciones sobre buenas y malas maneras de ser vecino, concepciones que fijan límites entre lo que resulta esperable y aprobable de un vecino y lo que no puede ser aceptado. Se presenta también esta construcción de alteridad entre vecinos, donde el vecino acusado por la agresión de su perro a una niña se enoja de que a él se lo juzga de "jodido", siendo "un laburante que apenas llego a los siete mil pesos de sueldo". A la vez las partes consideran que existen otros vecinos del barrio que cometen faltas que consideran peores a la que suscitó la controversia. Y asimismo se observa cómo la mediadora está preocupada por reconstruir el vínculo que antes mantenían las personas en controversia: "La mediadora opina que hay un punto en común que ambas familias sienten como pérdida, que es el contacto entre sus hijos" (p. 64). Para el autor este caso muestra de qué modo la vecindad configura un régimen contractual difuso, representando a la vez un valor y una manera singular de imaginar relaciones, pero en tanto se inserta en un régimen más amplio de intercambio social. Así, encuentra que esta categoría amplia organiza el tratamiento que los actores dan a sus conflictos, los hechos y las personas durante los procedimientos de mediación, y también la legitimidad del reclamo se enmarca en ese valor como referencia principal, definiendo sentidos de justicia y de juridicidad, de lo que resulta justo e injusto.

Volviendo a nuestro campo y fuera del ámbito vecinal, en una disputa por la organización de las visitas del padre al hijo en común, el mediador puede destacar en el acta de la audiencia que la demandante indica que el demandado es "buen padre". En otro caso donde se dirimía la cuota de alimentos, el demandado aducía: "no le voy a dar a ella para el baile y la pintura" en referencia a la mamá de sus hijos. "No lo está pidiendo para ella sino para los chicos" le indica la mediadora, intentando introducir en la negociación el "valor de las necesidades de los chicos" según explicaba la misma mediadora al reflexionar sobre su intervención en el caso. En una trama de contrato económico, el mediador también puede comunicar una supuesta atribución del denunciado de que el denunciante "es buen tipo" para hacer factible, en un asunto de estafa, la posibilidad de gestionar un acuerdo en mediación que evite el proceso judicial. En definitiva, como bien analiza Matta (2016), el valor de la relación social por encima de los intereses de las partes asume una importancia significativa en las audiencias de mediación.

\section{Palabras de cierre}

En este artículo nos hemos propuesto describir la manera en que la mediación (en este caso penal), como instancia singular de administración de conflictos, opone ciertas concepciones y rituales - sensibilidades legales-a los contornos conceptuales que ofrece 
la denuncia que le da origen. De algún modo, en esa transformación del conflicto desde una instancia a la otra, se manifiesta la naturaleza performativa de estas instituciones y del derecho en general. Al mismo tiempo este proceso configurativo del conflicto y su significado se revela en los usos que estas instancias pueden tener por parte de los propios participantes del sistema.

el trabajo describe cómo en la instancia de mediación se va desarmando el lenguaje penal contenido en la denuncia inicial, en cuanto por ejemplo a desagregar y ampliar el universo de cuestiones y actores implicados en la controversia, al igual que a redefinir los roles asignados de manera exacta a las partes en conflicto -víctimas y ofensores-. Se presentan también las tensiones entre cierta dimensión de publicitación que comporta el reclamo bajo el dispositivo de la denuncia y su tendencia a reprivatizarlo en la instancia de mediación, entre la pretensión desjudicializadora del dispositivo y el imaginario asociado a la sanción que movilizó ese reclamo primigenio.

Por otra parte las situaciones descriptas revelan un uso local de ciertos dispositivos para regular los conflictos, lo cual no implica necesariamente que las personas "hagan las cuentas judiciales" por ejemplo cuando realizan una denuncia, es decir, que imaginen el trayecto institucional completo y la inversión -de tiempo, exposición o recursos- que supondrá el proceso. Puede también haber un uso de la mediación en varios casos en un sentido análogo al de la denuncia, aunque no siempre ésta resulte en una alternativa cercana a su conocimiento local. Pero el caso es que estos diferentes usos y la legitimidad del reclamo se encuentran informados por evaluaciones que de algún modo tienen en cuenta los marcos de relaciones sociales más amplias en las que el conflicto es activado de mayor o menor compromiso moral, de mayor o menos asimetría y distancia social- y las posibles consecuencias sobre estas relaciones que comporta el recurso y participación en estas instancias. De ahí que también se sopese el valor del conflicto en sí -o de cargar con la atribución de ser una persona conflictiva - asociado también al hecho de litigar.

El trabajo también observa el modo en que conforme a una sensibilidad legal propia y a la necesidad de otorgar eficacia al trabajo del mediador, éste recurre a mecanismos de moralización del vínculo que subyace a la disputa, restando hostilidad y distancia entre las partes, al tiempo que las personas moralizan su posición en relación a la de sus oponentes para dar legitimidad al reclamo.

Podemos decir finalmente que la matriz conceptual y ritual de cada dispositivo habilita ciertas posibilidades en la manifestación del contenido significativo de los conflictos y su resolución y al mismo tiempo se cruza con distintas matrices de sociabilidad locales en las que estos cobran sentido. Dicho de otro modo, creemos que este trabajo señala un complejo enmarañado entre justicia y relaciones sociales, entre sensibilidades legales de los grupos sociales y de los operadores jurídicos que explican el sentido de las controversias y de la eficacia de determinadas alternativas institucionales para la atención de reclamos de naturaleza interpersonal. 


\section{BIBLIOGRAFÍA}

Amorim, M. S., Kant De Lima R. y Burgos, M. B. (Eds.). (2003). Juizados Especiais Criminais, sistema judicial e sociedade no Brasil: ensaios interdisciplinares. Niterói: Intertexto.

Auyero, J. y Berti, M. F. (2013). La violencia en los márgenes. Una maestra y un sociólogo en el conurbano bonaerense. Buenos Aires: Katz Editores.

Baptista, B. L. B. Mello, K., Filipo. K. y Borzino, Tais (2016). Fronteiras entre judicialidade e não judicialidade. Percepções e contrastes entre a mediação no Rio de Janeiro e em Buenos Aires. Revista de Estudos e Pesquisas sobre as Américas. Brasilia: Centro de Pesquisa e Pós-Graduação sobre as Américas (CEPPAC) de la Universidade de Brasília (UnB). vol. 10, n 1, 1-24 .

Bermúdez, N. (2015). “Algo habrán hecho". o de muertes más o menos merecidas. Revista DEODORO, Universidad Nacional de Córdoba, Año 5, № 5, julio, 8-8.

Bourdieu, Pierre. (1993). Los ritos como actos de institución. En J. Pitt-Rivers y J.G. Peristiany (Eds.) Honor y gracia, (pp. 111-123). Madrid: Alianza Universidad.

Bourdieu, P. (2001). La fuerza del derecho. Elementos para una sociología del campo jurídico. En P. Bourdieu Poder, derecho y clases sociales, (pp. 101-129). España: Editorial Desclée.

Cardoso de Oliveira, L. R. (2004). Honor, Dignidad y Reciprocidad. Cuadernos de Antropología Social, Facultad de Filosofía y Humanidades, UBA (20), 25-39.

Elias, N. (1997). Ensayo teórico sobre las relaciones entre establecidos y marginados. En N. Elias La civilización de los padres y otros ensayos, (pp. 79-138). Bogotá: Grupo editorial Norma.

Geertz, C. (1994). Conocimiento local: hecho y ley en la perspectiva comparada. En C. Geertz Conocimiento local. Ensayos sobre la interpretación de las culturas, (pp. 195-287). Barcelona: Paidós.

Godoy, Mariana I. (2016). Delito, conflicto: sensibilidades legales y trama institucional en el campo de la mediación penal en Salta-Argentina. Revista del Museo de Antropología. Facultad de Filosofía y Humanidades, Universidad Nacional de Córdoba. 2016 vol.9 n 1, 57-68.

Gluckman, M. (1963). Gossip and Scandal. Current Anthropology, Vol. 4, No. 3 (Jun., 1963). Universidad de Chicago, 307-316.

Kant de Lima, R. (2009). Por uma antropologia do dereito, no Brasil. En Ensaios de Antropologia e de Direito (R. Kant de Lima y M. Misse Coord.), (pp. 1-38). Rio de Janeiro: Lumen Juris Editora, 2da Edición.

Matta, J. P. (2016). Entre vecinos eso no se hace. Sentidos de justicia y de vecindad en el marco de un dispositivo institucional de administración de conflictos". Antípoda. Revista de Antropología y Arqueología, Enero-Abril, 55-71.

Matta, J. P. y Godoy, M. I. (2016). El movimiento de Mediación en Argentina: procesos, tensiones y afirmaciones. Revista de Estudos e Pesquisas sobre as Américas. Brasilia: Centro de Pesquisa e Pós-Graduação sobre as Américas (CEPPAC) de la Universidade de Brasília (UnB). Vol. 10, n 1 , $1-23$.

Mauss, M. (1979). Ensayo sobre los dones. Razón y forma del cambio en las sociedades primitivas. En M. Mauss Sociología y Antropología, (pp. 153-263). Madrid: Editorial Tecnos. 
Mello, K. S. S., \& Baptista, B. G. L. (2011). Mediação e conciliação no Judiciário: Dilemas e significados. DILEMAS: Revista de Estudos de Conflito e Controle Social, 4(1), 97-122.

Pita, M. V. (2010). Formas de vivir y formas de morir: los familiares de víctimas de la violencia policial. Buenos Aires: Editores del Puerto y CELS.

Rangel Torres de Mello V. C. (2013). A ambivalência de ser conciliador. Como eles se veem e são vistos. CONFLUÊNCIAS, Revista Interdisciplinar de Sociologia e Direito. Vol. 15, noํ 2, 61-74.

Redfield, R. (2005[1941]). La ley primitiva. Revista Mexicana de Sociología. Vol. 3, No. 2 (2nd Qtr., 1941). Versión en español de Oscar Richter, 17-44.

Sierra M. T. y Chenaut V. (2002). Los debates recientes y actuales en la Antropología Jurídica: las corrientes anglosajonas. En E. Krotz Antropología jurídica: perspectivas socioculturales en el estudio del derecho, (pp. 113-170). España: Anthropos Editorial y México: Universidad Autónoma Metropolitana, Iztapalpa.

Sigaud, L. (1996). Derecho y coerción moral en el mundo de los ingenios. Estudios históricos. Vol. 9. № 18, 361-388. Traducción de María Victoria Pita y María José Sarrabayrouse.

Sigaud, L. (2004). Armadilhas da honra e do perdão: usos sociais do direito na mata pernambucana. Mana vol.10 no.1 Rio de Janeiro, Abril, 131-163.

Simião, D. Barbosa V. Ferreira de Carvalho, N. Reis de Castro, L., Furiati, L. (2009). Para além da Lei: legalidade e eticidade na administração de conflitos em uma favela de Belo Horizonte. Ponencia presentada en la VIII Reunión de Antropología del Mercosur. Buenos Aires, 29 de septiembre al 2 de octubre.

Sinhoretto, J. (2010). Campo estatal de administração de conflitos: múltiplas intensidades da justiça. Anuário Antropológico/2009-2, 109-123.

Zenobi, D. (2014). Familia, política y emociones. Las víctimas de Cromañón entre el movimiento y el Estado. Buenos Aires: Antropofagia.

\section{NOTAS}

1. Agradezco a Juan Pablo Matta la lectura de una primera versión muy desordenada de este artículo y la lectura atenta de los evaluadores de la revista CORPUS que colaboraron en mejorar en mucho la calidad de esta presentación.

2. Este trabajo se realizó alternadamente entre los años 2012 y 2016 inclusive e incluyó la lectura de expedientes de mediación penal, conversaciones y entrevistas informales con mediadores y administrativos, especialmente en dos CM de la capital salteña, la observación del trabajo en mesa de entradas, de audiencias de mediación, la participación durante un año en reuniones periódicas de mediadores penales y civiles del Ministerio Público donde éstos intercambian experiencias sobre su práctica, entre otras instancias de interacción. Agradezco enormemente la predisposición y apertura de la directora de esta área institucional y de los mediadores de dicho ministerio.

3. La perspectiva procesual en el estudio del derecho, promovida especialmente por Laura Nader, indica la focalización en los procesos de disputa como parte de procesos sociales más extensos, es decir, atendiendo al vínculo de esas disputas con interacciones sociales y sistemas de obligaciones vinculantes entre los litigantes, además de considerar cómo las personas manipulan reglas e instituciones. Se puede ver una síntesis de este paradigma en Sierra y Chenaut (2002).

4. Es interesante que la socióloga brasileña Jacqueline Sinhoretto (2010) proponía, en vez de hablar de "campo jurídico" bajo la concepción de Bourdieu, referirse a un conjunto de rituales 
diversos que compiten entre sí o se refieren unos a los otros, entre los cuales se encontraba la mediación. Cabe señalar también que si bien en estas referencias estamos recuperando aportes para pensar el universo de lo jurídico, en otro texto se llama la atención sobre el hecho de que la mediación comprende una práctica que de algún modo desborda los contornos del derecho e incluso para su propia afirmación debe oponérsele y enfrentársele, al mismo tiempo que se articula problemáticamente con él (véase Matta y Godoy 2016).

5. Esta oposición entre la noción de conflicto y delito ha sido tratada en profundidad en Godoy (2016).

6. También el tema de la imprecisión y diversidad en torno al criterio de derivación y recepción de un caso en mediación penal fue trabajado en el mismo artículo mencionado.

7. No disponemos de datos cuantitativos al respecto, pero estamos en condiciones de aseverar de que se trata para los mediadores de un tema de recurrente análisis, puesto que la incomparecencia de las partes tiende a menoscabar la eficacia del sistema al restarle impacto estadístico.

8. A excepción de ciertos casos donde está comprendido un colectivo de damnificados o porta el riesgo de una conflictividad social mayor - como algunos casos de usurpación y eventualmente alguna estafa-.

9. Pues según argumentan estos autores, en estos lugares las distinciones entre lo legal y lo ilegal se desdibujan (existen en la trama del barrio negocios ilegales como el tráfico de drogas o propiedades irregulares de los terrenos o las viviendas) y por consiguiente los conflictos acostumbran a ser administrados de una manera poco institucionalizada. Auyero y Berti en referencia al conurbano bonaerense indicaban que el control territorial y arbitrario de la policía, articulado en muchos casos con el mundo criminal y frecuente activador de la violencia, predisponía a acudir poco a la policía para resolver un hecho de violencia, y que especialmente se desconfiaba de la policía en casos de violencia doméstica y de violencia sexual. Y Simião y sus colegas se refirieron asimismo a la recurrencia a múltiples fuentes de "derecho" o de autoridad para producir esas gestiones del conflicto en la favela estudiada, entre las que se encontraban los llamados Núcleos de Mediación y Ciudadanía, conformándose además otras autoridades legítimas como las del tráfico de drogas, que podían constituirse en agentes más eficaces y legítimos para resolver conflictos allí o ejercer una coerción efectiva sobre los moradores. Según aporta este trabajo existía una evaluación de parte de estas personas acerca de la eficacia y la legitimidad de esas autoridades para la administración de conflictos locales.

10. Así por ejemplo, en algunos conflictos por accidentes de tránsito donde no siempre las personas damnificadas cuentan con un representante legal que inicie una demanda penal y civil, la mediación se presenta como la posibilidad cierta de tomar conocimiento de la alternativa de asesorarse gratuitamente o en forma privada con un abogado y de solicitar algún tipo de compensación a la otra parte.

11. Registramos durante nuestro trabajo de campo un conjunto significativo de situaciones donde persiste en las personas que llegan a mediación la expectativa de encontrar algún mecanismo institucional de castigo a quien señalan como su ofensor, aunque esta expectativa pueda en no pocos casos diluirse, transformarse o suplirse por la propuesta conciliatoria.

12. En un trabajo de Matta (2016) sobre conflictos vecinales tratados en mediación sobre el que volveremos luego, se muestra cómo la relación de vecinos no necesariamente implica un trato cordial, sino más bien una relación de trato inexorable: "Más allá del saludo o no, vamos a tener que seguir siendo vecinos". Y también supone imaginar posibles intercambios a futuro: "Vos no sabés si el día de mañana por ahí llegás a necesitar algo".

13. Es interesante que la necesidad de situarse como víctimas moralmente reconocibles para sustentar el reclamo de justicia ha sido bastante descripta en un conjunto de investigaciones en el contexto de muertes violentas - especialmente de jóvenes-, perpetradas o reclamadas al Estado por parte de los familiares de estas víctimas, aunque no se ha explorado aún esta cuestión 
para este tipo de conflictos de bajo impacto penal. Tal calidad de víctima parece no estar entonces dada; en estas investigaciones se negocia en procesos de alta politización de familiares (Pita 2011), de definición de fronteras respecto a otros grupos sociales (Zenobi 2014), y donde el vínculo de parentesco tiene un componente central. Bermúdez (2015) describe el juego de acusaciones y juicio moral acerca de la reputación del joven muerto, que alcanzan incluso a su madre y que implican a vecinos y a la justicia. En los juicios por esas muertes se sopesan esas reputaciones en relación a la de los acusados -si tenían trabajo estable, si estudiaban, si tenían hijos reconocidos, si fumaban porro-. Su conclusión es que "los enjuiciamientos morales restringen el ya intrincado acceso a la justicia oficial y socavan las maneras en que las personas provenientes de sectores populares se conciben sujetos de derechos".

14. La "neutralidad" o "imparcialidad" del mediador respecto al contenido del conflicto, de cómo es interpretado por las partes y de las alternativas para su solución es un principio y valor importante para la práctica de la mediación, distinta a la neutralidad e imparcialidad del juez y el árbitro, que deben cuidar que las partes se conduzcan según las normas y leyes y que están obligados a disponer y resolver. Este es un aspecto que suscita no pocos debates teóricos en este campo.

\section{RESÚMENES}

En este artículo, a partir de un trabajo etnográfico realizado en distintos Centros de Mediación del Ministerio Público de Salta, Argentina, describimos la manera en que la mediación penal, como instancia singular de administración de conflictos de carácter interpersonal, opone ciertas sensibilidades legales -concepciones, lenguajes y rituales- a los contornos conceptuales que ofrece la denuncia penal que le da origen. De algún modo, en esa transformación del conflicto desde una instancia a la otra, se manifiesta la naturaleza performativa de estas instituciones y del derecho en general, de modo que el sentido del conflicto y del reclamo judicial se termina de configurar en contacto con estas instituciones en las que la controversia es sucesivamente procesada. Al mismo tiempo este proceso configurativo del conflicto y su significado se revela en los usos que de estos dispositivos, tanto de la denuncia como de la instancia de mediación, tienen los propios participantes del sistema. En estos diferentes usos, y para dar legitimidad al reclamo, víctimas y ofensores activan distintas evaluaciones que tienen en cuenta los marcos de relaciones sociales más amplias en las que el conflicto se ha activado - de mayor o menor compromiso moral, de mayor o menor asimetría y distancia social-y las posibles consecuencias sobre estas relaciones que comporta el recurso y participación en estas instancias institucionales.

In this article, and based on an ethnographic work conducted in different centers of mediation of the Public Ministry of Salta, Argentina, we describe the way criminal mediation-as a particular instance of interpersonal conflict management-opposes certain legal sensibilities, i.e. concepts, languages and rituals, to the conceptual boundaries of the criminal claims that originate the mediation. Somehow, the conflict transformation, from one instance to another, makes apparent the performative nature of these institutions and law in general, so that the sense of the conflict and the judicial claim take shape in contact with these institutions, where the controversy is successively processed. At the same time, this configuration process of the conflict and its meaning is revealed in the uses of these devices by the participants of the system, both in the complaint and the mediation instances. In these different uses, and to give legitimacy to the 
demand, victims and offenders activate different evaluations, which take into account broader frames of social relations where the conflict has occurred-greater or lesser moral commitment, varying asymmetry, social distance-and the possible influences on these relationships by the use and participation in these institutional spaces.

ÍNDICE

Keywords: Conflicts mediation, criminal complaint, legal sensibilities, uses of the law Palabras claves: Mediación de conflictos, denuncia penal, sensibilidades legales, usos del derecho

\section{AUTOR}

\section{MARIANA INÉS GODOY}

Instituto de Investigaciones en Ciencias Sociales y Humanidades-Consejo Nacional de Investigaciones Científicas y Técnicas-Universidad Nacional de Salta 